\title{
Current status of soil transmitted helminths and Schistosoma mansoni infection among children in two primary schools in North Gondar, Northwest Ethiopia: a cross sectional study
}

Biniam Mathewos ${ }^{1 *}$, Abebe Alemu $^{2}$, Desalegn Woldeyohannes ${ }^{5}$, Agersew Alemu², Zelalem Addis ${ }^{3}$, Moges Tiruneh ${ }^{3}$, Mulugeta Aimero ${ }^{4}$ and Afework Kassu ${ }^{3}$

\begin{abstract}
Background: School age children are one of the groups at high risk for intestinal parasitic infections especially in developing countries like Ethiopia as the supply of good quality drinking water and latrine coverage are poor. Though there are previous data on the prevalence of soil transmitted helminths (STHs) and Schistosoma mansoni infection among these high risk groups current status in the study area is unknown. Therefore, the aim of this study was to determine the current prevalence and associated risk factors of STHs and S. mansoni infections among school children.

Methods: A cross-sectional study was carried out in Gorgora and Chuahit towns, North Gondar Zone, North West Ethiopia from January 20 to February 25, 2012 involving 261 school children. A pre-tested and structured questionnaire was used to collect socio-demographic data and possible risk factors. Stool samples were collected and examined for intestinal parasites using Kato Katz method. Chi-square test was used to see if there is association between sociodemographic factors and other risk factors for STH and S. mansoni infection and odds ratio with 95\% $\mathrm{Cl}$ was computed as measures of association. $\mathrm{P}<0.05$ was taken as statistically significant.
\end{abstract}

Results: Out of the 261 study participants, 174 (66.7\%) were infected with one or more species of intestinal parasites. Ascaris lumbricoides was the predominant isolates (39.8\%) followed by Trichuris trichiura (6.1\%) and Hookworms (4.9\%). Schistosoma mansoni was detected in 33.7\% of the children. Among infected individuals, 9.5\% were coinfected by S. mansoni and A. lumbricoides and $1.5 \%$ with S. mansoni and T. trichiura. Swimming habit (OR: $2.536,95 \% \mathrm{Cl}: 1.122,5.737, \mathrm{P}=0.022$ ) was significantly associated with $\mathrm{S}$. mansoni infection.

Conclusion: The prevalence of STH and S. mansoni was high among school children. This should call for implementation of an integrated strategy to reduce morbidity and control of transmission of STH and S. mansoni.

Keywords: Soil transmitted helminths, Schistosoma mansoni, School children

\footnotetext{
* Correspondence: fikirbinny@gmail.com

${ }^{1}$ Department of Immunology and Molecular Biology, School of Biomedical and Laboratory Sciences, College of Medicine and Health Sciences, University of Gondar, Gondar, Ethiopia

Full list of author information is available at the end of the article
} 


\section{Background}

Soil transmitted helminthiasis and schistosomiasis are widely distributed and among the major medical and public health problems in many parts of the world. World Health Organization (WHO) estimated that 1.45 billion people are infected with $A$. lumbricoids, 1.3 billion with Hookworms and 1.05 billion with $T$. trichiura [1]. Schistosomiasis is also common in many parts of the world and about 200 million people are infected globally [2]. It is endemic in 76 countries and also it is one of a public health concern in developing countries. Approximately $80 \%$ of the 200 million people infected world-wide live in sub-Saharan Africa where S. mansoni is widespread $[3,4]$.

Ethiopia is a country with the lowest quality drinking water supply and latrine coverage in the world [5]. Hence, this unsafe and inadequate provision of water together with unhygienic living conditions and unsanitary waste management allow intestinal parasites and other communicable diseases to flourish in various localities [6]. As a result, intestinal parasites are common in most parts of Ethiopia and helminthic infections are the second most predominant causes of outpatient morbidity in the country. Among all of the helminthic infections, Ascariasis is the most prevalent in Ethiopia [7]. Schitosomiasis is also common in the area and if we see the distribution among the different parts of Ethiopia, it is a common disease in the northern region as compared to south and south west regions of Ethiopia [8].

Age is one of a risk factor for intestinal parasitic infection. Children who reach school age are at high risk for intestinal parasitic infections. Poor hygiene, low immune status, overcrowding, close contact with soil and to each other, lack of latrine, and low provision of water in schools are some of the factors that put school age children at high risk for intestinal parasitic infection [9].

Intestinal parasitic infections have known negative effects on the growth, appetite, and cognitive performance of school age children. Besides, the physical wellbeing and the active participation of school children will be compromised by these infections [10-13]. WHO emphasizes that appropriate treatment can reduce the burdon on majority of these children [14].

STHs and Schistosoma infections can be reduced based on interventions like regular anti-helminthic treatment, improved water supply, sanitation and health education [15]. STH infections have not been targeted for control in Ethiopia [16], though mass deworming as a component of the enhanced outreach strategy targeting under five children started in 2004 [17]. High coverage and low cost delivery of anti helminthic treatment has been achieved in some settings but improvement of sanitation is more complex since access to improved sanitation is very low in countries like Ethiopia [18,19].
Prevalence of intestinal helminths has been studied in different parts of Ethiopia [20-26]. However, the current prevalence of STH and schistosomiasis was not well addressed in different parts of Ethiopia including our study area. Therefore, the aim of this study was to determine the prevalence and associated risk factors of STHs and S. mansoni infection among primary school children of Chuahit and Gorgora towns, North Gondar, North West Ethiopia.

\section{Methods}

\section{Study design and area}

Cross-sectional study was conducted from January 20 to February 25, 2012 among primary school children of Gorgora and Chuahit towns of Dembia District, North Gondar Zone, northwest Ethiopia. Gorgora is a small but flourishing roadside town on the shore of Lake Tana (altitude $1800 \mathrm{~m}$ ), $65 \mathrm{kms}$ South of Gondar town. Chuahit is located to the north of Gorgora. The estimated total population in the two towns is estimated to be 2446 and 6,814 for Gorgora and Chuahit respectively [27]. The average temperature and humidity registered in both towns is $28^{\circ} \mathrm{C}$ and $22 \%$ respectively. Both of the towns have their own health centers that provide primary health care services including family health service, prevention and control of communicable diseases (malaria, HIV, tuberculosis, intestinal parasitic infections) and hygiene and environmental health. And both health centers also give diagnostic and treatment services for major infectious diseases of the area.

\section{Sample size and sampling technique}

The sample size was determined by using single proportion formula at $95 \%$ confidence interval (CI) level ( $\mathrm{Z}(1-\alpha / 2)=1.96)$. A prevalence of $67 \%$ was taken from similar study conducted before sixteen years ago in the same area [28]. A 5\% of marginal error was also taken. Therefore, sample size was calculated as $n=[Z 1-\alpha / 2] 2$ $\mathrm{P}(1-\mathrm{p}] / \mathrm{d} 2$, where: $\mathrm{n}$ is sample size, $\mathrm{P}$ is prevalence of parasites, Z $1-\alpha / 2$ is CI of $95 \%$, $d$ is marginal error to be tolerated [29]. By this calculation we obtained 340 to be the sample size. Since the total population in the two primary schools was less than 10,000 adjustment was made according to the formula; $\mathrm{nf}=\mathrm{ni} /(1+\mathrm{ni} / \mathrm{N})$ and a sample size of 254 was found. We added $10 \%$ for compensation of non-respondents and the final calculated sample size became 279 among whom 261 had participated in the study.

To determine the proportion of students to be selected from each of the two school and each sections, the sample size which was determined earlier was used. Each school had 10 sections therefore the total number of section was twenty. By dividing our sample size which was 261 by the number of total sections (20 sections), we obtained 13 study participants per one section. Therefore in each 
section 13 students and 14 from the last section has been taken by using simple random sampling method. To do this we used a table of random numbers to select study participants. As a sampling frame we used a registration list obtained from the schools.

\section{Data collection and processing Socio demography and risk factor assessment}

The study subjects were interviewed to assess whether they fulfill the already prepared inclusion criteria. The inclusion criteria that we used mentioned that those students whose parents or guardians were willing to give written consent and the students not taking anti helminthic drugs for the last 15 days were allowed to be included in this study.

Data on sociodemographic factors and other risk factors for STH and S. mansoni infection were collected using a structured questionnaire prepared for the purpose of this study. The questionnaire was prepared in English and then translated to the local language (Amharic) and checked for fitness. A pre-test was conducted on $10 \%$ of the school children that are not included in the study and appropriate corrections were made as the results found.

\section{Parasitological techniques}

Sufficient amount of single stool specimen (approximately $5 \mathrm{gm}$ ) was collected from each participant using a leak proof, tightly corked container. Samples were prepared using Kato-Katz technique as per the standard [30] and examined using X100 and X400 magnifications. The result was recorded carefully on well prepared format and finally it was attached with the respective questionnaire.

\section{Quality control}

The samples were examined within the 30 minutes of preparation of the sample. All slides were examined twice for confirmation of the result. From all of the slides, 15\% were randomly selected and re-examined at the end by experienced laboratory technologist who was blind for the first examination result.

\section{Data analysis}

Data was entered and analyzed using SPSS version 20 computer software after checking its completeness. Data was summarized in percentages and presented in tables. Association between risk factors and parasitological test results was assessed using odds ratio with $95 \% \mathrm{CI}$. P-value less than 0.05 were considered statistically significant.

\section{Ethical consideration}

The study was ethically approved by the ethical review committee of the school of biomedical and laboratory sciences, University of Gondar by the letter numbered SBLS/34/2012. The purpose of the study was communicated with Zonal health officers and informed consent was obtained from the parents/guardians of the students. Students infected with $S$. mansoni were treated with $40 \mathrm{mg} / \mathrm{kg}$ praziquantel (PZQ) and those infected with STHs were treated with $400 \mathrm{mg}$ albendazole (ALB).

\section{Results}

Sociodemographic characteristics of the study subjects

Among the 261children (139 males and 122 females), $147(56.3 \%)$ were from the town of Chuahit and 114 (43.7\%) from Gorgora. Majority, 224/261(85.8\%) study participants were in the age range from 5-15 years and also $157 / 261(60.2 \%)$ and $251 / 261(96.2 \%)$ were from farmer families and Christians respectively (Table 1).

\section{Prevalence of soil transmitted helminthes and schistosoma mansoni}

Out of the total study subjects, 174/261 (66.7\%) had one or more parasites. A. lumbricoides was the predominant isolate (104/261, (39.8\%) followed by Trichuris trichiura 16/261 (6.1\%) and Hookworms 13/261, (4.9\%). S. mansoni was isolated from $88 / 261(33.7 \%)$ of the study participants (Table 2). Co-infection rate was higher for S. mansoni and A. lumbricoides 25/261 (9.5\%) followed by $S$. mansoni and $T$. trichiura $4 / 261$ (1.5\%). There was a different trends on the prevalence of the parasite

Table 1 Sociodemographic characteristics of children attending Gorgora and Chuahit Elementary Schools, Northwest Ethiopia from January 20 to February 25, 2012

\begin{tabular}{llll}
\hline & Character & Frequency & Percentage \\
\hline Age & $<5$ & 8 & 3.1 \\
& $5-15$ & 224 & 85.8 \\
Sex & $>15$ & 29 & 11.1 \\
& Male & 139 & 53.3 \\
Religion & Female & 122 & 46.7 \\
& Christian & 251 & 96.2 \\
Ethnicity & Muslim & 9 & 3.4 \\
& Others & 1 & 4 \\
Educational level of & Amhara & 245 & 93.8 \\
the children & Tigrei & 11 & 4.2 \\
Address of the & Others & 5 & 2 \\
participant & Grade 5-8 & 109 & 58.2 \\
Family occupation & Gorgora & 147 & 41.8 \\
& Chuahit & 114 & 56.3 \\
& Farmer & 157 & 43.7 \\
& Merchant & 45 & 17.2 \\
& Government & 59 & 22.6 \\
\hline
\end{tabular}


Table 2 Prevalence of STH and S. mansoni in children attending Gorgora and Chuahit Elementary Schools, Northwest Ethiopia from January 20 to February 25, 2012

\begin{tabular}{|c|c|c|c|c|c|c|c|c|}
\hline \multirow[t]{2}{*}{ Parasite identified } & \multicolumn{2}{|c|}{ Male $(\mathrm{N}=139)$} & \multicolumn{2}{|c|}{ Female $(\mathrm{N}=122)$} & \multicolumn{2}{|c|}{ Total $(\mathrm{N}=261)$} & \multirow{2}{*}{$x^{2}$} & \multirow{2}{*}{ P-value } \\
\hline & $\mathrm{No}^{\circ}$ & & No\% & & No\% & & & \\
\hline S. mansoni & 40 & 28.7 & 48 & 39.3 & 88 & 33.7 & 3.324 & 0.072 \\
\hline A. lumbricoides & 57 & 41 & 47 & 38.5 & 104 & 39.8 & 0.167 & 0.683 \\
\hline T. trithiura & 7 & 5 & 9 & 7.3 & 16 & 6.1 & 0.619 & 0.431 \\
\hline Hookworms & 8 & 5.7 & 5 & 4 & 13 & 4.9 & 0.619 & 0.431 \\
\hline Others & 6 & 4.3 & 5 & 4 & 11 & 4.2 & & \\
\hline Total & 118 & 84.8 & 114 & 93.4 & 232 & 88.8 & & \\
\hline
\end{tabular}

among the different age groups in the different parasites (Figures 1 and 2).

\section{Risk factor analysis for soil transmitted helminthes and}

\section{S. mansoni}

Prevalence of $A$. lumbricoides and Hookworms were higher in male study participants while prevalence of $T$. trichiura and $S$. mansoni were higher in the females (Table 2). However there is no statistically significant association between parasite prevalence and being male and female $\left(\mathrm{X}^{2}=0.953\right.$, $\mathrm{p}$ value $\left.=0.335\right)$. Swimming habit $(\mathrm{OR}=2.536,95 \%$ CI $(1.122-5.735)$ showed statistically significant association with S. mansoni infection. However, there was no statistically significant association between other possible risk factors and STH and S. mansoni infection (Table 3).

\section{Discussion}

The overall prevalence of infection with STH and $S$. mansoni among school children of Gorgora and Chuahit towns, $66.7 \%$ was very high. This finding is in line with findings of a cross sectional survey conducted on STHs and S. mansoni infection among school children in Chilga district, northwest Ethiopia [20]. That study had reported an overall prevalence rate of $68.4 \%$. When specific parasitic prevalence is considered almost similarity was again observed in the prevalence of $A$. lumbricoides in that study (42.9\%, range: $22.9 \%-68.6 \%)$ and in the

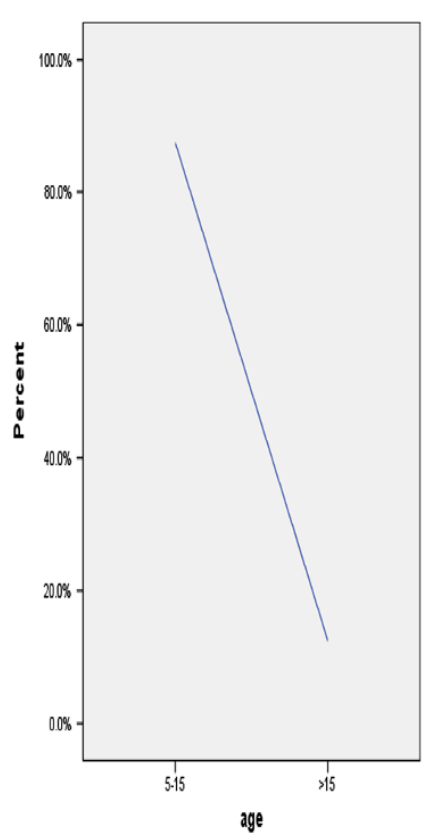

A

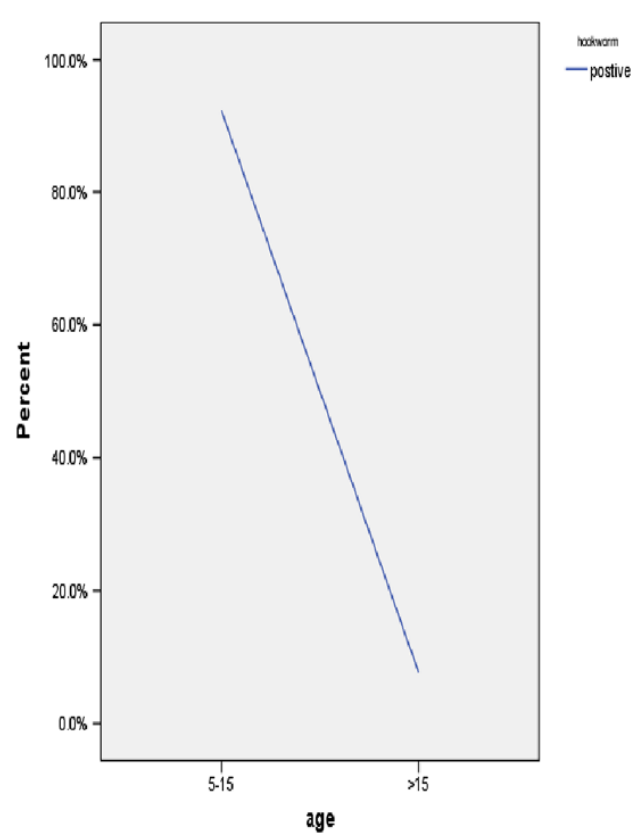

B

Figure 1 Prevalence of $T$. trichiura and Hookworms by age. A. Prevalence of T. trichiura by age among children attending Gorgora and Chuahit Elementary Schools, Northwest Ethiopia from January 20 to February 25, 2012. B. Prevalence of Hookworms by age among children attending Gorgora and Chuahit Elementary Schools, Northwest Ethiopia from January 20 to February 25, 2012. 


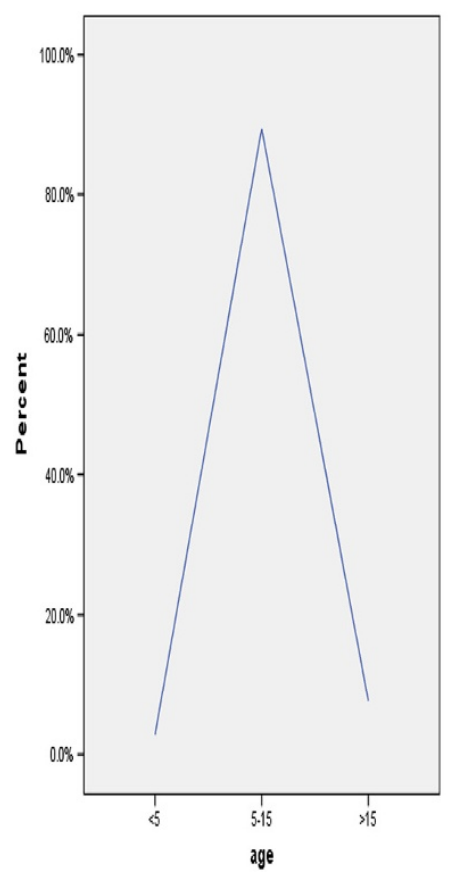

A

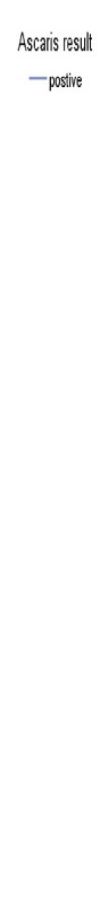

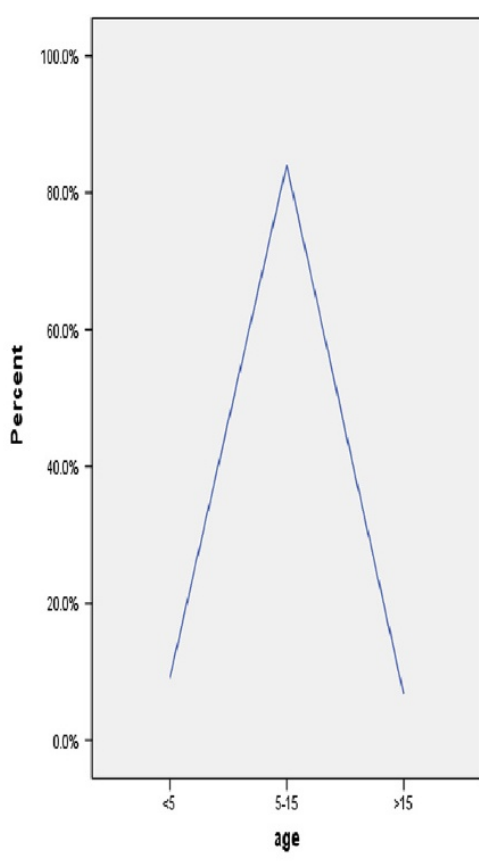

B

Figure 2 Prevalence of $\boldsymbol{A}$. lumbricoids and S. mansoni by age. A. Prevalence of A. lumbricoids by age among children attending Gorgora and Chuahit Elementary Schools, Northwest Ethiopia from January 20 to February 25, 2012. B. Prevalence of S. mansoni by age among children attending Gorgora and Chuahit Elementary Schools, Northwest Ethiopia from January 20 to February 25, 2012.

present study (39.8\%). However, in other parasites (other than A. lumbricoides) differences was observed between the two studies in that the findings of the that study showed a higher prevalence of Hookworms (37.7\%, range: $28.0 \%-65.5 \%)$, S. mansoni (19.4\%, range: $7.0 \%$ $64.3 \%$ ) and T. trichiura (14.8\%, range: $12.7 \%-20.8 \%$ ) than the present study which showed a prevalence of $4.9 \%$,
33.7\%, and 6.1\% for Hookworms, S. mansoni and T. trichiura respectively. Similarly a study conducted in Dembia plains has shown similar report to the present study with regards to the prevalence of $A$. lumbricoides and $S$. mansoni with infection rates of $41.3 \%, 35.0 \%$, respectively but difference was observed in prevalence of $T$. trichiura and Hookworms $16.5 \%$ and $22.8 \%$ respectively [22]. Such

Table 3 Risk factors for both soil transmitted heltminths and S. mansoni infection in children attending Chuahit and Gorgora Elementary School, Northwest Ethiopia, from January 20 to February 25, 2012

\begin{tabular}{|c|c|c|c|c|}
\hline Variables & N (\%) & STH and S. mansoni n\% & OR $(95 \% \mathrm{Cl})$ & P-value \\
\hline \multicolumn{5}{|l|}{ Sex } \\
\hline Male & 139(53.2) & $89(64)$ & $0.953(0.775-1.090)$ & 0.335 \\
\hline Female & $122(46.7)$ & 85(69.6) & 1 & \\
\hline \multicolumn{5}{|l|}{ Family } \\
\hline \multicolumn{5}{|l|}{ Occupation } \\
\hline Farmer & $157(60)$ & $110(70)$ & $0.581(0.467-1.243)$ & 0.081 \\
\hline Merchant & $45(17)$ & 19(42.2) & & 0.349 \\
\hline Government & $59(23)$ & $45(76.3)$ & $0.680(0.576-1.087)$ & 0.228 \\
\hline Employ & & & 1 & \\
\hline \multicolumn{5}{|l|}{ Address } \\
\hline Gorgora & 147(56.3) & 104(70.7) & $1.520(1.005-1.849)$ & 0.113 \\
\hline Chuahit & 114(43.6) & 70(61.4) & 1 & \\
\hline
\end{tabular}

Note: STHs = soil transmitted helminths $\mathrm{N}=$ total number of outcomes for each exposure. $\mathrm{N}=$ number of outcome for each exposure. 
differences in the prevalence of the specific parasites may be attributable to the difference in degree of suitableness of the macro and micro environment to the parasites in the different areas.

Higher prevalence in all of STH and S. mansoni parasites has been shown in other studies than the present study. For example, study conducted in school children in Adarkay District, northwest Ethiopia [21] showed a prevalence of $55.3 \%$ for S. mansoni, $43.0 \%$ for A. lumbricoides, $20.2 \%$ for Hookworms and $11.8 \%$ for T. trichiura. The differences in the prevalence might be due to variation among the two areas in water supply, socioeconomic status, and sanitation. Similarly a study conducted at Zarima town, northwest Ethiopia, showed a higher prevalence in all types of the parasites except for T. trichiura than the present study. In that study, overall prevalence of $82.4 \%$ was shown and a prevalence of $22 \%$, 19\%, 2.5\% and $37.9 \%$ was reported for A. lumbricoides, Hookworms, $T$. trichiura and $S$. mansoni respectively [31]. Some factors like environmental sanitation, personal hygiene, adequateness and quality of water, socioeconomic status, time of the study and climatic factors might be contributing for the difference in prevalence of the different parasites among the two different sites.

When we compare the findings of the present study about prevalence of $S$. mansoni with the study conducted previously in the same area which reported a prevalence of $67 \%$ [28], it showed that there is a remarkable decrement in the prevalence of the parasite. The progress in the decrement of the parasites prevalence could be due to different interventions that have been undertaken in the area like deworming and health education. However, the current prevalence cannot be considered to be low since it is still higher than findings of other studies conducted even in areas with higher risk for S. mansoni infection. For example in a study conducted at central and southern Tigray, one of the regions of Ethiopia, prevalence of $S$. mansoni was found to be $27 \%$ in longstanding irrigated areas, $10.8 \%$ in recently constructed irrigation schemes and $1.8 \%$ in the non-irrigated rural localities [32]. Similarly in Gondar town and surrounding areas, quite near to our study area, a prevalence of $35.6 \%$ was reported [23]. The reasons for higher prevalence of $S$. mansoni in the study area may be due to the fact that the study area is near to Lake Tana which is the biggest lake in the country and also the study area have many small water bodies that can be the sources of transmission for S. mansoni even though further extensive study is needed to verify the fact.

The high burden of STH and S. mansoni infection among school children of the study area may show that the children may be a potential source of infection and transmission for the diseases in the study area. Since it is well documented that these diseases are known to lower cognitive ability of students, low efficiency and productivity in their education endeavors may also be expected.

Other remarkable feature that has been shown from this study was high numbers of the children were infected with more than one type of worms. For example, one-tenth of the study participants were infected by both S. mansoni and A. lumbricoides. Such co-infections of $S$. mansoni and $A$. lumbricoides could be attributed to the co-endemicity of the two species and also poor sanitation in the study area. The finding of the present study was similar to study conducted in Cote d'Ivoire [33]. Coinfection may affect nutritional status of the children because of the combined effect of the different parasites that can deprive the important nutrients of the children.

When we analyze the risk factors associated with STH and $S$. mansoni infections, similar to a study conducted at Zarima town, northwest Ethiopia, the present study showed that $S$. mansoni infection had statistically significant association with swimming habit of school children similar to the present study [31]. The similarity may be because that both study area in near to water bodies in which swimming is common habit in both areas.

The strength of this study is; standard Kato Katz technique to detect ova of the parasites, qualified medical laboratory technologists and standard questionnaire were used. However, the study design (cross sectional) and the need to adjust the odds ratios for the effect of clustering by schools can be the limitations of the study.

\section{Conclusion}

The current prevalence is showing that STHs and $S$. mansoni are still a major health problem for the community. Even though there were few attempts made previously like community mobilization in the study area, it did not result in significant reduction in the diseases occurrence. Therefore, periodic and effective community mobilization, health education targeting behavioral change and in addition, well organized control strategy with de worming must be implemented so that significant reduction in prevalence of STHs and S. mansoni can be realized.

\section{Abbreviation \\ OR: Odds ratio; STHs: Soil transmitted helminths; SPSS: Statistical package for the social sciences; WHO: World Health Organization.}

\section{Competing interests}

The authors declare that they have no competing interests.

\section{Authors' contributions}

BM: initiation of the study, design, implementation, analysis and writeup. AA: implementation, analysis and write-up. AA: implementation. MT: design. MA: implementation. ZA: analysis and write-up. DW: analysis and write-up. AK: analysis and write-up. All authors read and approved the final manuscript. 


\section{Acknowledgements}

We would like to thank University of Gondar for financial support to conduct this study. The authors appreciate the study participants for their cooperation in providing the necessary information and stool sample. Great thanks go also to teachers and directors of Gorgora and Chuahit elementary school for the cooperation during data collection and also to Gorgora Health center for providing some laboratory materials. We would like to thanks also all data collectors and stool examiners for their great technical support.

\section{Author details}

'Department of Immunology and Molecular Biology, School of Biomedical and Laboratory Sciences, College of Medicine and Health Sciences, University of Gondar, Gondar, Ethiopia. ${ }^{2}$ Department of Medical Parasitology, School of Biomedical and Laboratory Sciences, College of Medicine and Health Sciences, University of Gondar, Gondar, Ethiopia. ${ }^{3}$ Department of Medical Microbiology, School of Biomedical and Laboratory Sciences, College of Medicine and Health Sciences, University of Gondar, Gondar, Ethiopia. ${ }^{4}$ Department of Biology, Faculty of Natural and Computational Sciences, University of Gondar, Gondar, Ethiopia. ${ }^{5}$ Department of Public Health, School of Medical and Health Sciences, Addis Ababa Science and Technology University, Addis Ababa, Ethiopia.

Received: 29 March 2013 Accepted: 6 February 2014

Published: 10 February 2014

\section{References}

1. World health organization: The prevention and control of schistosomiasis and soil transmitted Helminthiasis. Geneva: WHO; 2002.

2. World health organization. Weekly epidemiologic record. 2006; 81,145-164. http://www.who.int/wer/8116.pdf.accessed 12/11/2012.

3. Davis A, Cook C, Zumla A: Schistosomiasis: Manson's Tropical Diseases. 21st editionLondon: Elsevier Science; 2003:1431-1469.

4. WHO Expert Committee: Prevention and Control of Schistosomiasis and Soil-Transmitted Helminthiasis. In Technical Report Series. Geneva: WHO; 2002.

5. Kumie A, Ali A: An overview of environmental health status in Ethiopia with particular emphasis to its organization, drinking water and sanitation: a literature survey. Ethiop J Health Dev 2005, 19(2):89-103.

6. Ali H, Erku B, Woldemichael T, Kloos H: Schistosomiasis. The epidemiology and ecology of health and disease in Ethiopia. 1st editionAddis Ababa: Shama books; 2006:660-673.

7. Wodemichael T, Endeshaw T, Shibre T, Gebre T, Haddis M, Tilahun D: Intestinal parasitic infections in western Abaya with special reference to Schistosoma mansoni. Ethiop J Health Dev 1999, 13:25-26.

8. Haile G, Jirra C, Mola T: Intestinal parasitism among Jiren elementary and junior secondary school students, southwest Ethiopia. Ethiop I Health Dev 1994, 8:37-41.

9. Jarabo M, Garcia-Moran NP, Garcia-Moran Jl: Prevalence of intestinal parasites in a student population. Enferm Infecc Microbiol Clin 1995, 13:464-468.

10. De Silva NR, Guyatt HL, Bundy DA: Morbidity and mortality due to Ascarisinduced intestinal obstruction. Trans R Soc Trop Med Hyg 1997, 91:31-36.

11. Stephenson LS, Latham MC, Adams EJ, Kinoti SN, Pertet A: Physical fitness, growth and appetite of Kenyan school boys with hookworm, Trichuris trichiura and Ascaris lumbricoides infections are improved four months after a single dose of albendazole. J Nutr 1993, 123:1036-1046.

12. Nokes C, Bundy DA: Compliance and absenteeism in schoolchildren: Implications for helminth control. Trans R Soc Trop Med Hyg 1993, 87:148-152.

13. Hadidjaja P, Bonang E, Suyardi MA, Abidin SA, Ismid IS, Margono SS: The effect of intervention methods on nutritional status and cognitive function of primary school children infected with Ascaris lumbricoids. Am J Trop Med Hyg 1998, 59(5):791-795.

14. WHO: Diarrhoea. In Reducing Mortality From Major Killers Of Children: World Health Report Revised; 1998. Fact Sheet No: 178.

15. Albonico M, Montresor A, Crompton DW, Savioli L: Intervention for the control of soil transmitted helminthiasis in the community. Adv Parasitol 2006, 61:311-348.

16. Crompton DW: How much Helminthiasis is there in the World? $\mathrm{J}$ Parasitol 1999, 85:397-403.
17. World Bank: School Deworming at a Glance. Public Health at a Glance Series; 2003. Available at. http://www.dewormtheworld.org/sites/default/files/pdf/ DtW_AnnualReport_2009.pdf.

18. Tadesse Z, Hailemariam A, Kolaczinski JH: Potential for integrated control of neglected tropical diseases in Ethiopia. Trans R Soc Trop Med Hyg 2008, 102:213-214.

19. Federal Ministry of Health: Guidelines for the Enhanced Outreach Strategy (EOS) for Child Survival Interventions. Ethiopia: Addis Ababa; 2004.

20. Leykun J: Soil Transmitted Helminthic Infection and S. mansoni in School Children from Chilga District, North West Ethiopia. Ethiop J Health Sci 2001, 11:79-87.

21. Leykun J: Intestinal Helminthic Infection with Special Reference to $S$. mansoni in School Children in Adarkay District, North West Ethiopia. Ethiop J Health Dev 1997, 11:289-294.

22. Leykun J: Schistosomiasis mansoni and geo-Helminthiasis in school children in the Dembia Plains, Northwest Ethiopia. Ethiop J Health Dev 1998, 12:237-244.

23. Leykun J: Intestinal helminth infections in rural and urban school children in Gondar town and the surrounding areas, Northwest Ethiopia. SINET: Ethiop I Sci 1999, 22:209-220.

24. Aklilu L, Demisse M, Bahta M: Parasitiological survey of Addis Ababa and Debre Zeit school children with special emphasis on Bilharziasis. Ethiop Med J 1986, 6:1-7.

25. Mohammed A: Prevalence of Intestinal Parasites Kito Elementary School Children in Jimma Town, South West Ethiopia. Health student Research at Jimma University; 2003

26. Tsegaye S: Determining the prevalence of Intestinal parasites and Associated Risk Factors in Yebu Elementary School Students, Jimma Zone, South West Ethiopia. Student Research Programmed Community Based Education Jimma University; 2005.

27. Central Statistical Agency: Ethiopian demographic and health survey. Addis Ababa Ethiopia: National statistics; 2007.

28. Tiruneh M, Fantahun M, Kassu A, Tiruneh G, Van Lieshout L, Polderman A: Schistosoma mansoni in school attenders and non- attenders in Northwest Ethiopia. Ethiop J Health Dev 2001, 15:1-6.

29. Thrusfield M: Veterinary Epidemiology. London: Blackwell Science; 1995.

30. Katz N, Chaves A, Pellegrino J: A simple device for quantitative stool thicksmear technique in Schistosoma mansoni. Revista do Instituto deMedicina Tropical de São Paulo 1972, 14:397-400.

31. Alemu A, Atinafu A, Addis Z, Shiferaw Y, Teklu T, Mathewos B, Birhan W, Gebretsadik S, Gelaw B: Soil transmitted helminthes and Schistosoma mansoni infections among school childrens in Zarima town, Northwest Ethiopia. BMC Infect Dis 2011, 11:189-196.

32. Defenie T, Petros B: Irrigation practices and intestinal helminthes in Southern and Central Zone of Tigray. Ethiop J Health Dev 2009, 23(1):48-56.

33. Raso G, Lugibuhl A, Adjoua CA, Tian-Bi NT, Silue KD, Matthys B, Vounatsou P, Dumas ME, Holmes E, Singer BH, Tanner M, N'goran KE, Utzinger J: Multiple parasite infections and their relationship to self-reported morbidity in a community of rural Cote d'Ivoire. Int J Epidemiol 2004, 33:1092-1110.

\section{doi:10.1186/1756-0500-7-88}

Cite this article as: Mathewos et al:: Current status of soil transmitted helminths and Schistosoma mansoni infection among children in two primary schools in North Gondar, Northwest Ethiopia: a cross sectional study. BMC Research Notes 2014 7:88. 